\title{
Analysis of Facial Characteristics of Female Beauty and Age of Mona Lisa Using a Pictorial Composition
}

\author{
Niels Christian Pausch ${ }^{1^{\star}}$ and Christoph Kuhnt ${ }^{1}$ \\ ${ }^{1}$ Department of Oral, Craniomaxillofacial and Facial Plastic Surgery, University Hospital of Leipzig, \\ Liebigstraße 12, 04103 Leipzig, Germany.
}

Authors' contributions

This work was carried out in collaboration between both authors. Authors NCP and CK contributed equally to this work with regard to data acquisition, concept, review of the literature, image modification and writing of the article. Author CK contributed the statistics and wrote parts of the manuscript. Both authors read and approved the final manuscript.

Article Information

DOI: 10.9734/BJMMR/2017/33453

Editor(s):

(1) Medhat Emil Habib, Department of Plastic and Reconstructive Surgery, Zayed Military Hospital, Abu Dhabi, U.A.E. (2) Ravi Kumar Chittoria, Department of Plastic Surgery \& Advanced Centre For Microvascular, Maxillofacial \& Craniofacial, Laser Surgery, Jawaharlal Institute of Postgraduate Medical Education and Research, Pondicherry, India. (3) Emad Tawfik Mahmoud Daif Professor of Oral \& Maxillofacial Surgery, Cairo University, Egypt.

Reviewers:

(1) Luís Ricardo Martinhão Souto, Universidade de Marília (UNIMAR), Brazil.

(2) Shubhangi V. Agale, Grant Medical College, Mumbai, India. (3) Ahmad Rahhal, Arab American University, Palestine. (4) Alicia Noemi Kohli Bordino, Italian University Institute of Rosario, Argentina. (5) Adham Farouk, Alexandria University, Egypt. (6) Seung Chul Rhee, Dongguk University, South Korea. Complete Peer review History: http://www.sciencedomain.org/review-history/19580

Original Research Article

Received $16^{\text {th }}$ April 2017

Accepted $13^{\text {th }}$ June 2017

Published $17^{\text {th }}$ June 2017

\section{ABSTRACT}

Aims: The purpose of this study was to investigate the age of the Mona Lisa and the effect of painting composition on her beauty in terms of facial femininity, youthfulness, and attractiveness.

Study Design: We used a longitudinal study design.

Place and Duration of Study: We enrolled a random sample of dental students at the University of Leipzig, Faculty of Dental Medicine, between January 2015 and January 2016.

Methodology: The predictor variable was the portrait composition. To make the painting different, we substituted the faces in two other portraits (one male, Christian IV, Duke of Zweibrücken, and one female, Marie-Suzanne Giroust-Roslin) with that from the Mona Lisa. The outcome variables were estimated age, facial femininity, youthfulness, and attractiveness of the Mona Lisa. Appropriate descriptive and univariate statistics were calculated. The level of statistical significance was set at $P \leq 0.05$. 
Results: The sample comprised 107 subjects (76 females, $71 \%$; 31 males, $29 \%$ ) with a mean age of $24.8 \pm 2.6$ years. The panel estimated the Mona Lisa's age at $32.3 \pm 5.6$ years. Facial femininity, youthfulness, and attractiveness were affected by painting composition $(P<0.05)$.

Conclusion: The results of this study suggest the Mona Lisa's face is that of a woman in middleaged adulthood. Her facial femininity, youthfulness, and attractiveness depend on the composition of the painting.

Keywords: Mona Lisa; femininity; youthfulness; facial attractiveness; panel survey.

"... a beauty wrought out from within upon the flesh, the deposit, little cell by cell, of strange thoughts and fantastic reveries and exquisite passions".

Walter Pater (1839 - 1894) on Mona Lisa [1].

\section{INTRODUCTION}

The portrait known as the 'Mona Lisa' (French: La Joconde; Italian: La Gioconda) is arguably the most famous and readily recognized painting in the world. Public perception suggests she is one of the most beautiful women (the term "Mona Lisa" is used throughout the manuscript to refer both to the painting and to its subject). The portrait was painted by the Italian Renaissance master Leonardo da Vinci. Some believe it portrays the ideal woman, a drag queen, or even a self-portrait [2]. Others, however, accept that Lisa Gherardini was the painting's subject. After several unsuccessful pregnancies, she and her husband, Francisco del Giocondo-a wealthy silk merchant from Florence, Italy-celebrated their new child with this portrait. Leonardo spent four years, 1503-1507, painting this masterpiece, however. As a result, the portrait was refused by Francisco and remained in Leonardo's studio. Later, it was acquired by King Francis I of France. It is now owned by the French government and hangs in the Louvre Museum in Paris [2,3,4]. The artwork attracted much attention when it was stolen from the Louvre by Vincenzo Peruggia in 1911 and returned in 1913 [5].

Many investigators have examined the Mona Lisa, especially her smile. Adour [3] detected facial muscle contracture and synkinesis in the left side of the Mona Lisa's midface, suggesting recovery after Bell's palsy. Freud [6] stated that many portraits symbolized Leonardo's mother smile. Borkowski [7], however, suggested the Mona Lisa was not smiling but had lost her anterior teeth. A computerized 'emotion recognition' analysis of her face revealed $83 \%$ happy, 9\% disgusted, 6\% fearful and 2\% angry [4]. Other authors revealed the Mona Lisa's emotion to be perfect ambiguity between happy and sad [8].

Some details of Mona Lisa's face remain mysterious until today. The scar under the lower lip may be the result of injury with a blunt object. Her eyebrows appear depilated, but loss of the eyebrows and lashes might be a result of fading and overcleaning of the artwork during the centuries since its production. A yellow irregular leather-like spot on the left medial canthus and a bumpy swelling of the right index finger are indicative of xanthelasma and subcutaneous lipoma, respectively. Despite the absence of corneal arcus, these lesions are both suggestive of essential hyperlipidaemia, a strong risk factor of ischaemic heart disease, which might have caused her death. Lisa Gherardini died in 1516 at the age of $37[2,9]$.

Our literature search failed to identify any study addressing panel perceptions of the Mona Lisa's beauty.

The primary purpose of this study was to investigate the effect of painting composition on the Mona Lisa's beauty in term of facial femininity, youthfulness, and attractiveness. The null hypothesis was that different painting composition would not alter her facial femininity, youthfulness, and attractiveness. Other hypotheses were that the Mona Lisa's face in her portrait might appear younger, more feminine, and more attractive than her face in a male portrait, and would be more attractive than her face in a different female portrait. Our secondary purpose was to determine public perceptions of the Mona Lisa's age. The real age of the Mona Lisa was probably 23 or 24 years when the artwork was produced-assuming the woman portrayed really is Lisa del Giocondo. We hypothesized that, in the eyes of the panelists, the Mona Lisa would be in the third decade of life. 


\section{METHODOLOGY}

\subsection{Study Design and Sample}

We used a longitudinal study design to survey a random sample of fifth-year dental students at the University of Leipzig; a questionnaire and five portraits (Figs. 1-5) were used. All the participants were German and unknown to the data evaluators. One of the authors (N.C.P.) screened the subjects for study eligibility and initiated the consent process, including a review of study rationale and procedure. Informed consent was obtained from all participants. This study was exempt from review by our ethics committee. During the study, we observed the recommendations of the Helsinki declaration. There was no exclusion criterion for this study. The broad inclusion criteria provided the opportunity to enrol a diverse, heterogeneous sample, in the hope the results would be generally applicable.

\subsection{Variables and Data Collection}

Before the study, the questionnaire was tested for clarity by four pilot maxillofacial surgeons or trainees (two males and two females). The feedback from the pilot test helped us to eliminate any confusing or ambiguous items. During the experiment, the images were presented on a monitor screen. Distortion on the screen was adjusted until it was zero. Each portrait was shown to each panellist separately in a dark silent room, beginning with the male portrait with the Mona Lisa's face (Portrait 1) and ending with the original Mona Lisa (Portrait 5). The same experienced instructor (N.C.P.) chaired every rating procedure with ample time allowed, without coercion or recourse, and with a method for anonymous submission of the replies. All instructions were standardized and read from a paper to ensure the same information was given to all participants.

The predictor variable was portrait composition, which included male or female gender (binary variable). We used photographs of the original Mona Lisa, and randomly chose two portraits, which were painted after the Renaissance and have different backgrounds. To make the paintings different, we replaced the Mona Lisa with photographs of two other relatively unknown portraits (male, Christian IV, Duke of Zweibrücken; female, Marie-Suzanne GiroustRoslin). At the time their portraits were painted, the ages of Christian IV (Portrait 2) and MarieSuzanne Giroust-Roslin (Portrait 4) were 49 and 29 years, respectively (personal communication with the museums owning the portraits). All portrait modifications were done by N.C.P., by use of ArcSoft Photolmpressions 4.0 (ArcSoft Inc., Fremont, CA, USA) and Adobe Photoshop 7.0 (Adobe Systems Inc., San Jose, CA, USA).

The outcome variables included estimated age (years), facial femininity, youthfulness, and attractiveness of the person in each portrait. The observers were asked to estimate the Mona Lisa's age in years. For facial femininity, youthfulness and attractiveness, we used three 10-cm visual analogue scales: femininemasculine, old-young, and attractiveunattractive. The values 0 in the three different visual analogue scales were defined as feminine or young or attractive face and 10 as masculine or old or unattractive face.

\subsection{Data Analysis}

The results collected were initially entered into Excel spreadsheets (Microsoft Corp., Redmond, WA, USA) and then transferred to SPSS (Version 10.0; SPSS, Inc., Chicago, IL, USA) databases for analysis. Descriptive and univariate statistics were computed as indicated.

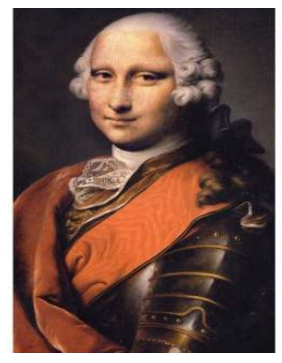

Fig. 1. Male portrait with the Mona Lisa's face

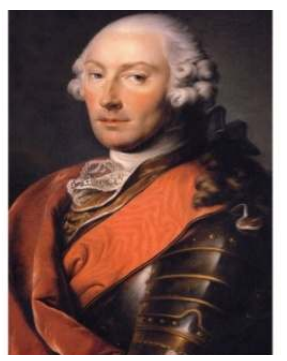

Fig. 2. Christian IV - Duke of Zweibrücken

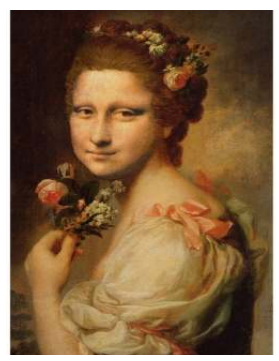

Fig. 3. Female portrait with the Mona Lisa's face

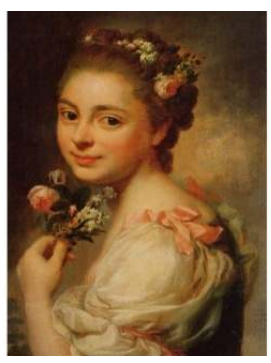

Fig. 4. MarieSuzanne Giroust-Roslin

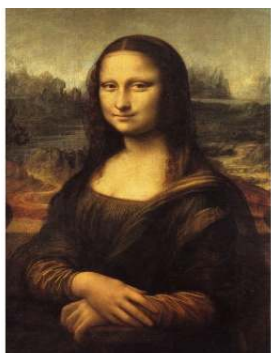

Fig. 5. Mona Lisa 
A $P$-value of $\leq 0.05$ was regarded as indicative of statistical significance. Complete data and details of the questionnaires are not reported, but are available on request.

\section{RESULTS AND DISCUSSION}

The study sample consisted of 107 subjects (76 females, $71 \%$; 31 males, 29\%), mean age $24.8 \pm 2.6$ years. The panellists estimated the Mona Lisa's age at $32.3 \pm 5.6$ years. They voted that the male portrait with the Mona Lisa's face was younger and more feminine, but less attractive, than the original male portrait $(P<0.05)$. Compared with the original female portrait, that with the Mona Lisa's face looked older and more attractive $(P<0.05)$. The facial femininity, youthfulness, and attractiveness of the original Mona Lisa were judged higher than those of the male portrait with the Mona Lisa's face, but lower than those of the female portrait with the Mona Lisa's face $(P<0.001)$. Details are given in Table 1. No participant recognized the Mona Lisa's face in portraits 1 and 3 until they saw the original Mona Lisa at the end of the survey.

The first purpose of the study was to investigate the effect of painting composition on the Mona Lisa's facial beauty, in terms of facial femininity, youthfulness, and attractiveness. It was shown statistically that her facial femininity, youthfulness, and attractiveness were affected by the composition of the painting $(P<0.05)$. Our secondary purpose was to determine how old Mona Lisa was. We hypothesized her age would be in the third decade of life. Results from this study indicated that the estimated age of the Mona Lisa's face was $32.3 \pm 5.6$ years. The male portrait with the Mona Lisa's face was rated younger and more feminine, but less attractive than the original male portrait. Mona Lisa's face made the person in the female portrait look older, but more attractive. The femininity, youthfulness, and attractiveness of the Mona Lisa were regarded as less than those of the female portrait with Mona Lisa's face. Surprisingly, Mona Lisa's face remained unrecognised and was accepted as masculine in the portrait of a male.

Our findings sustain the controversies regarding the sitter in the portrait of the Mona Lisa. Some suggest Leonardo used himself as the model. Use of androgynous figures is common in Renaissance art, especially in 15th and early 16th century Italian art. Leonardo spent many years painting the Mona Lisa; he lived in households without women and travelled a lot during the period the Mona Lisa was being painted. No record of the model for the portrait, nor a commission, payment, or preliminary study for this work have been identified. The contrived dress with no accompanying emblems, jewellery, or accessories, together with the slightly masculine face (e.g. supraorbital bossing) differ greatly from standards for conventional female models [10]. The high hairline of the Mona Lisa might be a renaissance fashion, but is also a feature of masculinity [11]. Other artworks by Leonardo, for example the portrayal of St John the Baptist (produced in the years 1513-1516) continue the presentation of sexual ambivalence. Although the striking resemblance of St John the Baptist to the Mona Lisa creates the illusion that the model for St John might have been a relative of Mona Lisa, the similarity of the two portraits might be because both artworks represent human average faces without facial gender explicitness. Such gender ambiguity is absent from copies of the Mona Lisa, probably produced by other artists, for example the 2012 rediscovered Prado version [12]. The averageness of the Mona Lisa's face might, moreover, be a reason for the limited aesthetic assessment by the panellists in our study. Average faces may be attractive, but are also slightly boring, whereas very attractive faces are usually a pleasant contrast to total averageness [13].

Lin et al. [14] analysed the Mona Lisa and Leonardo's self-portraits by using a computerized active shape model based on 87 landmarks derived from 488 frontal human faces. They observed different features and gender differences between the two faces. A computerbased picture-processing technique revealed that Leonardo's self-portraits and the Mona Lisa portrayed the same face, however. X-ray studies have revealed a 'hidden' portrait of Isabelle, Duchess of Aragon, beneath the 'surface' painting of the Mona Lisa. Leonardo lived in the Palace of Ludovico Sforza, Duke of Milan, from 1483 to 1499 . As the court painter, he did many paintings ranging from Sforza's mistresses to the Duchess and her children. It is, therefore, possible that Leonardo later substituted his own features for those in the original sketch of Isabelle. Indeed, Leonardo was familiar with symbolic philosophizing associated with androgyny, which may have led to self-portraits in women's clothes. He appeared in court twice accused of homosexuality and sodomy. The dichotomy of the different landscapes on either side of the Mona Lisa may be a clue to the 
Table 1. Univariate associations among the study variables

\begin{tabular}{|c|c|c|c|c|c|c|c|c|}
\hline \multirow[t]{2}{*}{ Portrait $^{\star}$} & \multicolumn{2}{|c|}{ Facial femininity $^{\Lambda}$} & \multicolumn{2}{|c|}{ Facial youthfulness $^{\Lambda}$} & \multicolumn{2}{|c|}{ Facial attractiveness $^{\Lambda}$} & \multicolumn{2}{|c|}{ Estimated age } \\
\hline & Mean \pm S.D & $P$-value & Mean \pm S.D & $P$-value & Mean \pm S.D & $P$-value & Mean \pm S.D & $P$-value \\
\hline 1 & $6.38 \pm 1.72$ & $<0.001 \dagger$ & $4.39 \pm 1.52$ & $<0.001 \dagger$ & $6.30 \pm 1.63$ & $0.002 \dagger$ & $34.80 \pm 9.09$ & $<0.001 \dagger$ \\
\hline 2 & $8.46 \pm 1.37$ & & $5.61 \pm 1.38$ & & $5.58 \pm 1.65$ & & $46.05 \pm 6.14$ & \\
\hline 3 & $1.72 \pm 1.12$ & 0.298 & $2.87 \pm 1.58$ & $<0.001 \dagger$ & $3.62 \pm 1.37$ & $0.0007 \dagger$ & $25.87 \pm 4.72$ & $<0.001 \dagger$ \\
\hline 4 & $1.89 \pm 1.26$ & & $1.75 \pm 2.16$ & & $4.38 \pm 1.84$ & & $18.03 \pm 3.51$ & \\
\hline 1 & $6.38 \pm 1.72$ & $<0.001 \dagger$ & $4.39 \pm 1.52$ & $<0.001 \dagger$ & $6.30 \pm 1.63$ & $<0.001 \dagger$ & $34.80 \pm 9.09$ & $<0.001 \dagger$ \\
\hline 3 & $1.72 \pm 1.12$ & & $2.87 \pm 1.58$ & & $3.62 \pm 1.37$ & & $25.87 \pm 4.72$ & \\
\hline 5 & $3.13 \pm 1.67$ & & $4.14 \pm 1.24$ & & $4.73 \pm 1.42$ & & $32.28 \pm 5.62$ & \\
\hline
\end{tabular}

gender combination [10]. The lack of sexuality or clearly defined female beauty of the Mona Lisa may explain why her femininity is less than that of Marie-Suzanne Giroust-Roslin in our study.

Although the Mona Lisa is a painting, with a halffantasy landscape in the background, her face is life-like in appearance [10]. Leonardo used an isosceles triangle with the golden proportions to organize the Mona Lisa's portrait. Her face was placed at the upper vertex of the triangle, resulting in the geometric aspect of the proportions and the magnetic smile [7]. Although a more stylish hairstyle with fashionable clothing and modern makeup would make the Mona Lisa look more attractive, Thomas [4] suggested that her beauty derived from several factors: (1) the symmetry and anatomical proportions as in the rules of 'horizontal thirds', 'vertical fifths', and 'symmetrical harmony' of the face, (2) the natural and unaltered appearance, and (3) the strong cheekbones. The secret of her smile may be linked to the 'sfumato' technique [15]. This painting technique blurs and shadows the image; creating an ambiguous appearance until appreciation the art becomes no more and no less than the imagination of the observer $[4,10,16,17,18]$. The unearthly effect of the artwork is increased by the specific gaze arrangement of Mona Lisa's eyes, which seem to follow the viewer around the room $[19,20]$.

Some authors believe that people's views of facial attractiveness are consistent, irrespective of race, nationality, culture, and social status [21]. Others found that attractiveness of a humans face is strongly influenced by race and sex [22]. In the survey by Magro (1997), panellists were asked to choose attractive features of phenotypic traits that are either no longer prevalent among humans (primitive) or have become increasingly prevalent (derived). Several derived traits (e.g. high forehead, large eyes, oval-shaped face, straight and closely spaced teeth, and orthognathic chin) were linked with the attractiveness of Barbie dolls. Magro reached the conclusion that derived anatomic traits were perceived as more attractive than primitive traits and that the Barbie doll shows us what we wish to be [22]. Mona Lisa's face clearly differs from that stereotype. A slightly reddish skin (indicating good blood circulation) is moreover, regarded as attractive and healthy [23]. Different facial colour compositions (red/green/blue) may affect the perceived age of a person's face [24]. In the Mona Lisa portrayal, red pigment (vermilion) has faded away over the centuries, and yellowish and grey colours dominate the face. This might be one reason for the perceived lack of attractiveness and youthfulness of the Mona Lisa in our study. The relatively high frontal hairline contributes to this effect, because an exposed forehead is somewhat associated with mature age [25]. As a result, the perceived age of the Mona Lisa was rated older than expected.

In our study, the compositions of the paintings affect the Mona Lisa's beauty. The effect of painting composition on panellist perception confirms previous studies of the Mona Lisa [26]. All the participants claimed they did not recognize the face until shown the original Mona Lisa portrait. Our finding suggests that painting composition has a greater effect on visual processing than the Mona Lisa's face.

This study has limitations. First, the gender distribution within the panel was not balanced (there were more female panellists), which might affect our results. Second, monitor presentation of the painted artworks might result in colours different from those of the original painting. Third, the real age of the person portrayed in the Mona Lisa will remain unknown until her identity is clarified. And, fourth, the results of our study cannot be generalized. The number of assessed portrayals was relatively small. Mona Lisa's face 
was inserted in paintings from the 18th century with strong gender specificity because of typical hairstyle, clothes, and accessories. The results may differ if portraits from other centuries or with other styles are used.

\section{CONCLUSION}

In contemporary perception of female attractiveness, the Mona Lisa is not an outstanding beauty. Her facial expression, age, and gender remain unclear. In the eyes of young adults, this results in a less attractive and youthful appearance. Her face does not convey absolute loveliness. The strong effect on the observer is a product of the mystic smile and the deft gaze. The ambiguity of the subject's expression is an ideal average rather than a real woman's face. The composition of the painting has a greater effect than the face itself.

\section{CONSENT AND ETHICAL APPROVAL}

This study was exempted from the institutional ethical review because it did not involve human subjects directly. Informed consent was obtained from all participants.

\section{ACKNOWLEDGEMENTS}

We wish to thank the Faculty of Dental Medicine of the University of Leipzig and the Museums: Louvre, Paris, France (Fig. 5); Bayerische Staatsgemäldesammlung, Munich, Germany (Fig. 2); and Malmö Konstmuseum, Sweden (Fig. 4), for their permission and cooperation. We wish to thank Dr. Pitak-Arnnop for scientific advice.

\section{COMPETING INTERESTS}

Authors have declared that no competing interests exist.

\section{REFERENCES}

1. Pater W. The renaissance. Studies in Art and Poetry: Leonardo da Vinci. EBook; 1869.

(Accessed 22 November 2016)

Available:http://www.gutenberg.org/files/23 98/2398-h/2398-h.htm\#leonardo

2. Dequeker J, Muls E, Leenders K. Xanthelasma and lipoma in Leonardo da Vinci's Mona Lisa. Isr Med Assoc J. 2004; 6:505-6.
3. Adour KK. Mona Lisa syndrome: solving the enigma of the Gioconda smile. Ann Otol Rhinol Laryngol. 1989;98:196-9.

4. Thomas JR. More than a pretty face: The Mona Lisa. Arch Facial Plast Surg. 2008; 10:65-6.

5. Harris JC. Leonardo da Vinci's Mona Lisa. JAMA Psychiatry. 2013;70(6):555-6.

6. Freud S. Leonardo da Vinci and a memory of his childhood. New York: WW Norton. 1964;62.

7. Borkowski JE. Mona Lisa: The enigma of the smile. J Forensic Sci. 1992;37:170611.

8. Kontsevich L, Tyler C. What makes Mona Lisa smile? Vision Res. 2004;44:1493-8.

9. Ose L. The real code of Leonardo da Vinci. Curr Cardiol Rev. 2008;4:60-2.

10. Schwartz LFF. The Mona Lisa identification: Evidence from a computer analysis. Vis Comput. 1988;4:40-8.

11. Shams MG, Motamedi MH. Case report: feminizing the male face. Eplasty. 2009; 9:8-14.

12. Carbon CC, Hesslinger VM. Da Vinci's Mona Lisa entering the next dimension. Perception. 2013;42(8):887-93.

13. Alley TR, Cunningham MR. Averaged faces are attractive, but very attractive faces are not average. Psychol Sci. 1991; 2:123-5.

14. Lin D, Tu J, Rajaram S, Zhenqiu Z, Huang T. Da Vinci's Mona Lisa: A modern look at a timeless classic. Lect Notes Comput Sci. 2006;4299:123-8.

15. Ruhemann H. Leonardo's use of sfumato. Br J Aesth. 1961;1:231-7.

16. Ball P. Behind the Mona Lisa's smile. Nature. 2010;466(5):694.

17. Livingstone $\mathrm{M}$. Is it warm? Is it real? Or just low spatial frequency? Science. 2000; 290(5495):1299.

18. Soranzo A, Newberry M. The uncatchable smile in Leonardo da Vinci's La Bella Principessa portrait. Vision Res. 2015; 113(A):78-86.

19. Koenderink JJ, van Doorn AJ, Kappers AM, Todd JT. Pointing out of the picture. Perception. 2004;33(5):513-30.

20. Boyarskaya E, Sebastian A, Bauermann T, Hecht $\mathrm{H}$, Tüscher $\mathrm{O}$. The Mona Lisa effect: neural correlates of centered and offcentered gaze. Hum Brain Mapp. 2015; 36(2):619-32.

21. Magro AM. Why Barbie is perceived as beautiful. Percept Mot Skills. 1997;85:36374. 
22. Kramer RS, Jones AL, Sharma D. Sequential effects in judgements of attractiveness: The influences of face race and sex. PLoS One. 2013;2;8(12): e82226.

23. Fink B, Neave N. The biology of facial beauty. Int J Cosmet Sci. 2005;27:317-25.

24. Burt DM, Perrett DI. Perception of age in adult caucasian male faces - computer graphic manipulation of shape and color information. Proc R Soc Lond Ser B Biol Sci. 1995;259,137-43.

25. Rassman WR, Pak JP, Kim J. Phenotype of normal hairline maturation. Facial Plast Surg Clin North Am. 2013;21(3):31724.

26. Carbon CC, Hesslinger VM. Stable aesthetic standards delusion: Changing 'artistic quality' by elaboration. Perception. 2014;43:1006-1013.

(C) 2017 Pausch and Kuhnt; This is an Open Access article distributed under the terms of the Creative Commons Attribution License (http://creativecommons.org/licenses/by/4.0), which permits unrestricted use, distribution, and reproduction in any medium, provided the original work is properly cited.

Peer-review history:

The peer review history for this paper can be accessed here:

http://sciencedomain.org/review-history/19580 